\title{
Impact of Different Illumination Conditions on Visual Caries Detection with ICDAS
}

\author{
Klaus W. Neuhaus Edi Jasarevic Adrian Lussi \\ Department of Preventive, Restorative and Pediatric Dentistry, University of Bern, Bern, Switzerland
}

\author{
Key Words \\ Caries diagnostics · Reliability · Sensitivity · Specificity · \\ White light
}

\begin{abstract}
The aim of this study was to test the influence of different degrees of additional illumination on visual caries detection using the International Caries Detection and Assessment System (ICDAS). Two calibrated examiners assessed 139 occlusal surfaces of extracted permanent molars using a standard operation lamp with or without an additional headlamp providing three default brightness intensities. Histology served as the gold standard. Pooled data showed no differences in sensitivities. Specificities were not influenced by additional light. The area under the curve for the Marthaler classification $D_{3}$ threshold was significantly lower when an additional strong headlamp was used $0.59 \mathrm{com}$ pared to $0.69-0.72$ when reduced illumination intensities were used). One of the two examiners also had a significantly lower sensitivity for the $D_{1}$ threshold when an additional headlamp was used. The use of additional white light led to a reduced detection of dentine lesions.
\end{abstract}

(c) 2015 S. Karger AG, Basel
Visual-tactile caries detection is dependent on the ability of the dentist to see the tooth surfaces. Consequently, recommendations have been provided that we need 'good lighting' [Howat, 1981; Nyvad et al., 2008], 'adequate light' [Lussi, 1993] or 'good illumination' [Buchalla, 2010]. Backer Dirks et al. [1961] reported using a 'torchlight with high intensity' to carry out investigations or having used a small 'mouthlight' without specifying further [Backer Dirks, 1966]. 'Strong light' was also reported to help to differentiate between fluoride and non-fluoride enamel opacities [Russell, 1961]. However, there seems to be, as yet, no consensus on what the optimum illumination should be. Is it maximum illumination? When we have a look at what is commonly used for illumination at the dental chair (LED, xenon), there seems to be a clear trend toward the use of stronger and more powerful illumination with both operation lamps and additional headlamps [C. Engelhart, KaVo, Germany, pers. commun.]. Headlamps with a self-reported brightness of 70,000$80,000 \mathrm{~lx}$ are available on the market.

The first signs of dental caries are conspicuously characterized by a change of translucency and light refraction. Because visual caries detection is based on the interplay of reflected and transmitted light, it is worth examining

PD Dr. Klaus Neuhaus, MMA, MAS REST DENT

Freiburgstrasse 7

CH-3010 Bern (Switzerland)

E-Mail klaus.neuhaus@zmk.unibe.ch 
the effect of different illumination conditions on visual inspection.

The working hypothesis of the present study was that additional light has no impact on the diagnostic outcome of the International Caries Detection and Assessment System ICDAS [2005].

\section{Materials and Methods}

\section{Tooth Selection and Preparation}

A total of 139 permanent molars were chosen from a pool of extracted, irreversibly anonymized teeth stored in $1 \%$ chloramine solution at $4{ }^{\circ} \mathrm{C}$. Informed consent was obtained from the donors to use their teeth for scientific purposes. The chosen teeth had no fillings, no hypomineralization and no obvious cavities.

Soft tissue was removed with a curette. The crowns of the teeth were cleaned using air abrasion with sodium bicarbonate for up to 15 s (Prophyflex, KaVo, Biberach, Germany), without damaging the tooth surface [Neuhaus et al., 2010]. The teeth were then gently rinsed with a water-air spray for $10 \mathrm{~s}$ and stored in $1 \%$ chloramine solution in separate tightly lockable containers. The occlusal surfaces of the teeth were then digitally photographed at a magnification of $\times 6.25$ (Leica M420, Heerbrugg, Switzerland). The site of interest was marked with an arrow on a printout of the photograph.

\section{Examiners}

Two examiners conducted the assessments. They were both familiar with the ICDAS. One examiner had 2 years of clinical experience; the other examiner had 10 years of clinical experience. The senior examiner was previously trained (weighted kappa $>0.75$ in a different ICDAS study) and calibrated the younger examiner by training with extracted teeth and the use of e-learning software. The natural visual acuity of the examiners was tested using a miniaturized near vision test [Eichenberger et al., 2011]. Examiners were asked to wear their usual visual correction devices (lenses, glasses). For reasons of caries detection bias, no magnification devices were allowed [Neuhaus et al., 2015]. Both examiners had a visual acuity $>1$.

\section{Caries Assessments}

The caries assessment was carried out according to the ICDAS criteria and took place under the same standardized conditions. A second assessment was performed 1 week later. The examiners were blinded to their previous results and to the results of the other examiner. The illumination conditions during visual assessment were: 1 Standard operation lamp at arm's length (Häubi AG, Lyss, Switzerland), working distance $350 \mathrm{~mm}$ (SOL)

2 SOL plus additional white light headlamp (Power X-Light, Keydent ADSystems, Vaterstetten, Germany), working distance $350 \mathrm{~mm}$, weak default (SOLw); 8,070 lx

3 SOL plus additional white light headlamp (Power X-Light), working distance $350 \mathrm{~mm}$, medium default (SOLm); 14,908 lx 4 SOL plus additional white light headlamp (Power X-Light), working distance $350 \mathrm{~mm}$, strong default (SOLs); 22,800 lx

The headlamp (Power X-Light) was chosen because it is the only model on the market with three pre-adjusted degrees of brightness.

\section{Headlamp Measurement}

The headlamp was measured at the Federal Institute for Metrology in Bern. Both brightness and the Colour Rendering Index (CRI) were assessed, and a spectral analysis was performed. Brightness was measured at a distance of $350 \mathrm{~mm}$ with a calibrated lux meter in a dark environment. A laser beam was used to precisely position the headlamp perpendicularly to the measuring device. Illumination intensity was measured in the middle of the light spot. The measured CRI was 75 . There was a spectral gap at the wavelength range of $450-525 \mathrm{~nm}$.

\section{Histology}

The crowns were separated using a diamond disc (Isomet 111180 low speed saw, Buehler Ltd., Lake Bluff, Ill., USA; $101.67 \mathrm{~mm}$ diameter, $0.3 \mathrm{~mm}$ thickness). Each tooth was then ground longitudinally up to $1 \mathrm{~mm}$ from the measurement site on a Knuth Rotor polishing machine (Struers, Ballerup, Denmark) with silicone carbide paper of $60 \mu \mathrm{m}$ grain size under cooled tap water. The progression of the grinding process was constantly checked under a microscope (Leica) at a magnification of $\times 6.25$. When the periphery of the site was reached, silicone carbide paper with a grain size of $30,18,8$ and $5 \mu \mathrm{m}$ was sequentially used. Photographs of the ground site were taken at $\times 6.25$ using a microscope (Leica). The cut surfaces were cleaned and stained with rhodamine B (Inselspital-Apotheke, Bern, Switzerland). The surfaces were then photographed at $\times 10$ (Leica) and scored by two experienced examiners using the Marthaler classification [1966]: $\mathrm{D}_{0}=$ no caries; $\mathrm{D}_{1}=$ caries extending to the outer half of enamel; $\mathrm{D}_{2}=$ caries extending to the inner half of enamel; $\mathrm{D}_{3}=$ caries extending to the outer half of dentine; $\mathrm{D}_{4}=$ caries extending to the inner half of dentine.

Histology served as the gold standard for further statistical evaluation.

\section{Statistics}

The ICDAS scores were translated into histological scores as follows: ICDAS $0=\mathrm{D}_{0}$; ICDAS $1=\mathrm{D}_{1}$; ICDAS $2=\mathrm{D}_{2}$; ICDAS 3, $4=\mathrm{D}_{3}$; ICDAS 5, $6=\mathrm{D}_{4}$. The calculation of sensitivities, specificities and area under the curve (AUC) of receiver-operating characteristics were calculated with $\mathrm{R}$ software ( $\mathrm{R}$ Development Core Team v2.15.1, Vienna, Austria). Sensitivities and specificities were compared using the McNemar test, and AUCs were compared according to the method of Lee and Rosner [2001]. Intra- and interexaminer reliabilities were tested using weighted kappa statistics with $\mathrm{R}$ software. The level of significance was set at $\mathrm{p}<0.05$.

\section{Results}

The histological scores were $\mathrm{D}_{0}=30, \mathrm{D}_{1}=25, \mathrm{D}_{2}=34$, $\mathrm{D}_{3}=29$ and $\mathrm{D}_{4}=21$.

The pooled data show a significantly smaller AUC at the $\mathrm{D}_{3}$ threshold when SOLs was used (table 1). An analysis of single examiners showed a significantly reduced sensitivity for the senior examiner when SOLm or SOLs were used at the $\mathrm{D}_{1}$ threshold: 0.9 (SOL) and 0.82 (SOLw) compared to 0.76 (SOLm) and 0.75 (SOLs). Specificities 
Table 1. Diagnostic accuracy under different illumination conditions (pooled data)

\begin{tabular}{llllll}
\hline & & SOL & SOLw & SOLm & SOLs \\
\hline $\mathrm{D}_{1}$ & Sensitivity & $0.84^{\mathrm{a}}$ & $0.82^{\mathrm{a}}$ & $0.78^{\mathrm{a}}$ & $0.76^{\mathrm{a}}$ \\
& Specificity & $0.78^{\mathrm{a}}$ & $0.77^{\mathrm{a}}$ & $0.92^{\mathrm{a}}$ & $0.88^{\mathrm{a}}$ \\
& AUC & $0.81^{\mathrm{a}}$ & $0.79^{\mathrm{a}}$ & $0.85^{\mathrm{a}}$ & $0.82^{\mathrm{a}}$ \\
\hline $\mathrm{D}_{3}$ & Sensitivity & $0.73^{\mathrm{a}}$ & $0.69^{\mathrm{a}}$ & $0.71^{\mathrm{a}}$ & $0.59^{\mathrm{a}}$ \\
& Specificity & $0.86^{\mathrm{a}}$ & $0.87^{\mathrm{a}}$ & $0.86^{\mathrm{a}}$ & $0.87^{\mathrm{a}}$ \\
& AUC & $0.8^{\mathrm{a}}$ & $0.78^{\mathrm{a}}$ & $0.79^{\mathrm{a}}$ & $0.73^{\mathrm{b}}$
\end{tabular}

Different superscript letters within each row represent statistically significant differences $(\mathrm{p}<0.05)$.

Table 2. Intra- and interexaminer reliability (weighted kappa)

\begin{tabular}{llll}
\hline & $\begin{array}{l}\text { Intra- } \\
\text { examiner } 1\end{array}$ & $\begin{array}{l}\text { Intra- } \\
\text { examiner } 2\end{array}$ & $\begin{array}{l}\text { Inter- } \\
\text { examiner }\end{array}$ \\
\hline SOL & 0.93 & 0.86 & 0.8 \\
SOLw & 0.93 & 0.92 & 0.82 \\
SOLm & 0.91 & 0.89 & 0.84 \\
SOLs & 0.89 & 0.91 & 0.84 \\
\hline
\end{tabular}

were not significantly influenced by the different illumination conditions (range: $0.73-0.93$ ).

Intra- and interexaminer reliabilities remained unchanged under different illumination conditions (table 2).

Cross-tabulations indicate that ICDAS score 0 was given more often under stronger illumination conditions (SOLs), while ICDAS codes 3 were recognized less often under these conditions (table 3 ).

\section{Discussion}

In this in vitro experiment, we found that our hypothesis had to be rejected because an additional strong headlamp can negatively influence visual caries detection: ICDAS score 0 was given more often under strong illumination (SOLs), and particularly the detection of localized enamel breakdowns seemed to be hampered under these illumination conditions. This was particularly remarkable considering that the detection of dentine lesions usually requires operative intervention.

In a dental setting, the illumination intensity in the mouth is recommended to be $8,000 \mathrm{~lx}$ to at least $15,000 \mathrm{~lx}$
Table 3. Cross-tabulations (pooled data)

\begin{tabular}{|c|c|c|c|c|c|c|c|c|}
\hline \multirow{2}{*}{$\begin{array}{l}\text { Illumination } \\
\text { condition }\end{array}$} & \multirow{2}{*}{ Histology } & \multicolumn{6}{|c|}{ ICDAS codes (pooled) } & \multirow[t]{2}{*}{ Sum } \\
\hline & & 0 & 1 & 2 & 3 & 4 & 5 & \\
\hline \multirow[t]{6}{*}{ SOL } & $\mathrm{D}_{0}$ & 47 & 8 & 4 & 1 & 0 & 0 & 60 \\
\hline & $\mathrm{D}_{1}$ & 23 & 11 & 13 & 3 & 0 & 0 & 50 \\
\hline & $\mathrm{D}_{2}$ & 10 & 12 & 25 & 20 & 0 & 1 & 68 \\
\hline & $\mathrm{D}_{3}$ & 2 & 3 & 19 & 31 & 1 & 2 & 58 \\
\hline & $\mathrm{D}_{4}$ & 0 & 0 & 3 & 10 & 2 & 27 & 42 \\
\hline & Sum & 82 & 34 & 64 & 65 & 3 & 30 & 278 \\
\hline \multirow[t]{6}{*}{ SOLw } & $\mathrm{D}_{0}$ & 46 & 7 & 5 & 2 & 0 & 0 & 60 \\
\hline & $\mathrm{D}_{1}$ & 25 & 10 & 13 & 2 & 0 & 0 & 50 \\
\hline & $\mathrm{D}_{2}$ & 12 & 12 & 24 & 19 & 1 & 0 & 68 \\
\hline & $\mathrm{D}_{3}$ & 3 & 3 & 21 & 23 & 5 & 3 & 58 \\
\hline & $\mathrm{D}_{4}$ & 0 & 0 & 4 & 12 & 1 & 25 & 42 \\
\hline & Sum & 86 & 32 & 67 & 58 & 7 & 28 & 278 \\
\hline \multirow[t]{6}{*}{ SOLm } & $\mathrm{D}_{0}$ & 55 & 1 & 4 & 0 & 0 & 0 & 60 \\
\hline & $\mathrm{D}_{1}$ & 32 & 2 & 12 & 3 & 1 & 0 & 50 \\
\hline & $\mathrm{D}_{2}$ & 13 & 12 & 22 & 19 & 1 & 1 & 68 \\
\hline & $\mathrm{D}_{3}$ & 4 & 2 & 19 & 24 & 9 & 0 & 58 \\
\hline & $\mathrm{D}_{4}$ & 0 & 0 & 4 & 12 & 2 & 24 & 42 \\
\hline & Sum & 104 & 17 & 61 & 58 & 13 & 25 & 278 \\
\hline \multirow[t]{6}{*}{ SOLs } & $\mathrm{D}_{0}$ & 53 & 2 & 5 & 0 & 0 & 0 & 60 \\
\hline & $\mathrm{D}_{1}$ & 33 & 2 & 11 & 4 & 0 & 0 & 50 \\
\hline & $\mathrm{D}_{2}$ & 15 & 14 & 20 & 18 & 0 & 1 & 68 \\
\hline & $\mathrm{D}_{3}$ & 5 & 1 & 27 & 17 & 6 & 2 & 58 \\
\hline & $\mathrm{D}_{4}$ & 0 & 0 & 8 & 8 & 2 & 24 & 42 \\
\hline & Sum & 106 & 19 & 71 & 47 & 8 & 27 & 278 \\
\hline
\end{tabular}

(DIN EN ISO 9680:2013 [Deutsches Institut für Normung, 2013]). This performance is usually achieved by the use of standard operation lamps. The advantage of using an additional headlamp in a dental setting is obvious: when illuminating the oral cavity with an operation lamp, vision is obstructed by the lips, cheeks and tongue at the lingual surfaces in the lower jaw or the distobuccal surfaces in the upper jaw. In contrast, the co-axial light beam of a headlamp allows for shadow-free illumination of otherwise difficult-to-reach areas.

For detection of white spot lesions, contrast sensitivity is required for good results, while for the detection of microcavities good visual acuity is required. Visual acuity has been shown to begin deteriorating at the age of 40 [Eichenberger et al., 2013]. In addition, contrast sensitivity has been shown to deteriorate as soon as the age of 40 [Liutkeviciene et al., 2013]. We found that the senior examiner (almost 40 years old) in the present study appeared to be sensitive to bright illumination and suffer from reflection glare. 
Furthermore, with respect to lesion activity assessment, it is important to judge the glossiness of a white spot lesion, because, different from active, matte-looking lesions, inactive lesions are usually shiny and are not indicated for professional treatment [Nyvad et al., 2003]. Yet, inactive enamel lesions are not shiny per se. They rather become shiny through illumination, i.e. light that enters the surface and gets reflected. In other words, visual caries detection thus works by discriminating colour contrasts and different surface reflection intensities, or by discriminating different degrees of so-called albedo. A spectral and angular dependence of albedo has been described [Coakley, 2003]. Both dependencies could have an influence on the visual perception of caries. The emitted spectrum of the LED headlamp was found to be somewhat different from an operation lamp. A spectral gap was measured between the wavelengths of 450 and 525 $\mathrm{nm}$. This is intended, because dentists are supposed to wear a headlamp all day long, and unintentional initiation of lucerine/camphor chinone-induced photopolymerization is thus prevented. Consequently, the colour rendering by a headlamp is not the same as by a standard operation lamp, which usually has a CRI $>90$. This could affect the visualization of dentine caries, and in fact the AUC dropped significantly in the present study at the $\mathrm{D}_{3}$ threshold. A second possible influencing factor is the angulation of the light. Co-axial light from headlamps reflects more directly into the eye than oblique incipient light from operation lamps. Strong incipient light may cause blooming of the tooth surface, and thus reduce the perception of contrast of the visible structures. It seems reasonable to suggest blooming of the surface and examiner's glare as possible reasons for the present findings.

According to the set-up of this study, it appears that reflection glare and age-related contrast sensitivity play a role in visual caries detection under strong illumination conditions. Therefore, strong additional light (i.e. $>20,000 \mathrm{~lx}$ ) should not be used for visual caries detection. Examiners intending to use head-mounted lamps (e.g. for caries detection trials under field conditions) should check the brightness of their lamps, because dentine caries lesions might be overlooked. The topic warrants further research.

\section{Acknowledgements}

The statistics were performed by Lukas Martig, Institute of Actuarial Science and Mathematical Statistics, from the University of Bern. Measurements of the headlamp were performed by Dr. Peter Blattner, METAS. Our lab technician Isabelle Hug performed the histology. Their work is much appreciated and herewith acknowledged.

\section{Disclosure Statement}

There is no conflict of interest.

\section{References}

Backer Dirks O: Posteruptive changes in dental enamel. J Dent Res 1966;45:503-511.

Backer Dirks O, Houwink B, Kwant GW: The results of $6^{1 / 2}$ years of artificial fluoridation of drinking water in the Netherlands. The TielCulemborg experiment. Arch Oral Biol 1961; 5:284-300.

Buchalla W: Die tägliche Herausforderung: Praxis der Kariesdiagnostik. Zahn Prax 2010;1:1-7.

Coakley JA: Reflectance and albedo, surface; in Curry JA, Webster PJ (eds): Thermodynamics of Atmospheres and Oceans. Int Geophys 2003;65:1914-1923.

Deutsches Institut für Normung: Zahnheilkunde Behandlungsleuchten DIN EN ISO 9680. 2013.

Eichenberger M, Perrin P, Neuhaus KW, Bringolf $\mathrm{U}$, Lussi A: Influence of loupes and age on the near visual acuity of practicing dentists. J Biomed Opt 2011;16:035003.

Eichenberger M, Perrin P, Neuhaus KW, Bringolf $\mathrm{U}$, Lussi A: Visual acuity of dentists under simulated clinical conditions. Clin Oral Investig 2013;17:725-729.
Howat AP: A comparison of the sensitivity of caries diagnostic criteria. Caries Res 1981;15: 331-337.

International Caries Detection and Assessment System (ICDAS) Coordinating Committee: Rationale and evidence for the International Caries Detection and Assessment System (ICDAS II). 2005/2011. www.icdas.org (accessed October 18, 2015).

Lee M-LT, Rosner BA: The area under correlated receiver operating characteristic curves: a nonparametric approach based on generalized two-sample Wilcoxon statistics. Appl Stat 2001;50:337-344.

Liutkeviciene R, Cebatoriene D, Liutkeviciene G, Jasinskas V, Zaliuniene D: Associations between contrast sensitivity and aging. Medicina 2013;49:273-277.

Lussi A: Comparison of different methods for the diagnosis of fissure caries without cavitation. Caries Res 1993;27:409-416.
Marthaler TM: A standardized system of recording dental conditions. Helv Odontol Acta 1966;10:1-18.

Neuhaus KW, Ciucchi P, Donnet M, Lussi A: Removal of enamel caries with an air abrasion powder. Oper Dent 2010;35:538-546.

Neuhaus KW, Jost FN, Perrin P, Lussi A: Impact of different magnification levels on visual caries detection with ICDAS. J Dent 2015, Epub ahead of print.

Nyvad B, Fejerskov O, Baelum V: Visual-tactile caries diagnosis; in Fejerskov O, Kidd EAM (eds): Dental Caries - The Disease and Its Clinical Management. Oxford, Blackwell Munksgaard, 2008, pp 49-68.

Nyvad B, Machiulskiene V, Baelum V: Construct and predictive validity of clinical caries diagnostic criteria assessing lesion activity. J Dent Res 2003;82:117-122.

Russell AL: The differential diagnosis of fluoride and non-fluoride enamel opacities. J Public Health Dent 1961;21:143-146. 